\title{
DEVONI RAUAKONKRETSIOONID VEERISTENA KVATERNAARISETETES
}

Lõuna-Eesti Põlva-Võru vahelisel alal leidub liustikujõgede kruusades rohkesti mitmesuguse kujuga götiidikonkretsioone. Neis sisalduva liiva mineraalne koostis on lähedane keskdevoni Burtnieki lademe liivakivide omale, mistõttu on ilmne konkretsioonide pärinemine nende kivimite paljanditest Ahja jõe orus. Konkretsioonide suure hulga sattumist hilisemasse kruusa võis soodustada oru laiusesuunaline asend ja looklev kuju. Nimetatud tegurid võimendasid liustiku eksaratsiooni selles piirkonnas.

Põlva-Võru vahelisel alal Lõuna-Eestis leidub teele veetud kruusas rohkesti mugula- või koorikukujulisi raudhüdroksiididest kujundatud tumepruune kivimkehi, mille päritolu kohta puudusid seni usaldusväärsed ancmed. Esialgne uuring näitas, et need kivid pärinevad peamiselt Karioja orundis paiknevatesse oosidesse rajatud kruusavõtukohtadest - Marimäe ja Kuningamäe karjääridest (Pirrus, Puustusmaa, 1991). Välisilmelt võis neid pidada kohalikust aluspõhjast pärinevateks konkretsioonideks, kuid kuna teated niisuguste moodustiste kohta aluspōhjakivimitest olid üpris napid (Девон и карбон Прибалтики, 1981, lk. 137), tuli pidada võimalikuks ka nende kaugemat, erraatilist päritolu. Leidude suur hulk kruusas viitas nende kivide üsnagi rikkale allikale mandrijää kulutustegevuse vööndis.

Probleemi edasisel uurimisel selgusidki monned uued asjaolud. Piirkonna kruusakarjääride süstemaatiline ülevaatus näitas, et konkretsioonidega on rikastunud üsna kitsas meridionaalne vöönd piki Ora-Karijõe orundit (joon.). Lääne pool - Saverna kruusavõtukohtades - need kivid kaovad, ida pool puuduvad piisavad kontrollivõimalused, kuid üksikleidudest on teateid veel Värskast ja isegi Petseri lähikonnast.

Oluline on aga materjali iseloomu muutus põhjast lõunasse. Kui lõunapoolsemates leiukohtades (Kuningamäe, Marimäe, Lauga) esineb see ümbriskivimitest täielikult välja prepareerunud muguljate ümarvormide või ümardunud plaadikatketena, siis põhja pool lisanduvad suuremad vormitud lahmakad, nurgelised tükid ja kärgjalt koorikulised karkassvormid, mille tühikutes võib näha ka kollaseks oksüdeerunud liiva. Kõige põhjapoolsemas, Kooskora leiukohas, Põlvast $7 \mathrm{~km}$ pōhja pool, täheldati ka õhukesi, mõne millimeetri paksusi rauakoorikuid, mida võib leida ka Taevaskoja piirkonna Burtnieki liivakivide paljandeist. Satuti isegi otsesele tõendile - rüükala hambale ühes plaatjas vormis.

* Eesti Teaduste Akadeemia Geoloogia Instituut. Estonia pst. 7, EE-0105 Tallinn, Estonia.

** Eesti Geoloogiakeskus. Piiri 5, EE-3053 Keila, Estonia, 
Kivimmaterjali ülevaatusel meenus E. Kurikule, et 1950, aastatel leidis ta ühest Taevaskoja ümbruse paljandist, praeguseks vee alla jäänud nn. Kindapäka mäelt suure konkretsioonilis-koorikulise moodustise mōōtmetega $1 \times 1,1 \times 1,8 \mathrm{~m}$. Sellal ei pälvinud see küll rohkemat tähelepanu, kuid välipäevikusse tehtud detailjoonis ei jäta kahtlust, et niisugused moodus-

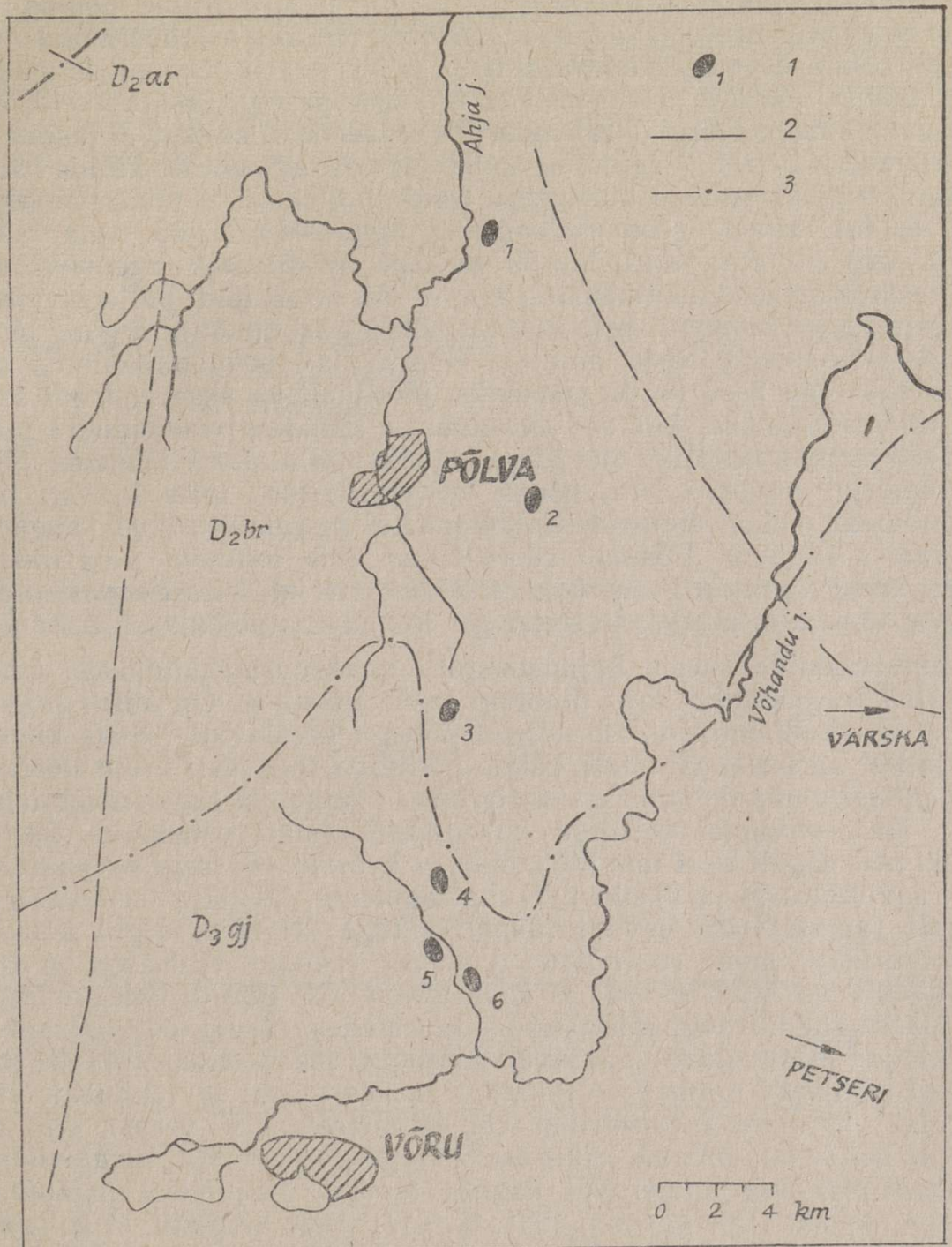

Devoni rauakonkretsioonide leiud kvaternaari liustikujõesetetes.

1 - leiukohad (1 - Kooskora, 2 - Lutsu, 3 - Naruski, 4 - Lauga, 5 - Marimäe, 6 - Kuningamäe), 2 - konkretsioonide levikuala piir, 3 - Aruküla, Burtnieki ja Gauja lademe avamusalade piir.

Finds of Devonian iron concretions in Quaternary glaciofluvial sediments.

1 - Outcrops (1 - Kooskora, 2 - Lutsu, 3 - Naruski, 4 - Lauga, 5 - Marimäe, 6 - Kuningamäe), 2 - the distribution boundary of concretions, 3 - the distribution boundary of Aruküla, Burtnieki, and Gauja regional stages. 
tised olidki lähteallikaks lähikonna kvaternaarisetetes esinevatele konkretsioonifragmentidele. Nimetatud uurija osutas veel teiselegi seesuguste konkretsioonide leiukohale, ja nimelt Riia lahe idarannikul, Burtnieki liivakivide avamuspiirkonnas. See näitab, et konkretsioonid neis kihtides olid regionaalselt laialdase levikuga ja et nende sattumine mandrijää poolt ümberpaigutatud kuhjatistesse on igati seaduspärane.

Peab aga märkima, et konkretsioonifragmentide koondumisel just Võru-Põlva vahelisse piirkonda pidi olema mingi eriline põhjus. Uks põhjusi võiks olla konkretsioonide erakor dselt rikkalik moodustumine nimetatud piirkonna devoni kivimites, midagi postsedimentatsioonilise maagistumise taolist. Paraku ei ole meil selle kohta praegu faktandmeid. Andmete puudumine mõistagi ei tähenda, et konkretsioonikoldeid ei tasuks just siit sihikindlalt otsida. Vastupidi, konkretsioonifragmentide küllus kvaternaarisetetes lausa suunab uuringule. Kuid on olemas ka teine tähelepanu vääriv eeldus, nimelt geomorfoloogiline tegur. Mandrijää teele jäänud Ahja ürgorg oli oma aluspõhjajärsakutega kahtlemata intensiivsemaid eksaratsioonibarjääre liustikumassi teel - siit rebiti lahti palju kiviplokke ja pihustati need moreeni. Just Põlvast põhja pool on Ahja ürgorg järsult hambuliste loogetega. Need muutsid liikuva jää kokkupuutepinna aluspõhjajärsakutega $2-3$ korda pikemaks, järelikult ka eksaratsiooni samavõrra intensiivsemaks, kui see avaldunuks lihtsama orukontuuri puhul. Siit võiski moreen kohaliku aluspõhja materjaliga oluliselt täieneda. Nimetatud materjal pudenes oma nõrga tsementeerituse tõttu kiiresti laiali ning vabastas endas leiduvad konkretsioonid ja rauakoorikud kaugemale kanduvate veeristena. Edasine rikastumine võis toimuda juba liustikujõgedes, mille voolusängides konkretsioonimaterjal koos Fennoskandiast pärineva tugevate aluskorraveeristega munakate põhimassi moodustab.

Konkretsioonide eneste kujunemispilti on kruusalasunditesse ümberpaigutatud fragmentide järgi muidugi raske taastada. On siiski selge, et tegemist on raudhüdroksiidide nõrgvormidega liivakivides. Seda kinnitab liivateradest karkassi säilimine kõigis götiidiga tugevasti tsementeerunud kehades. Sealjuures on konkretsiooniprotsess kulgenud sageli selektiivselt, valides ümbriskivimist eelkõige jämedateralisemad vahekihid. Seetōttu kohtabki neis sageli 3-4 mm läbimõõduga kvartsi- või isegi päevakiviteri, samuti saviveeriseid ja üksikuid faunafragmente, mistōttu tsementeeritud materjali samastamine devoni tüüpkivimitega tekitaski algul kōhklusi. Jämepurrurikkad mõne sentimeetri paksused läätsjad kihikesed on Burtnieki liivakivides siiski olemas ja konkretsioonilise götiidi ladestumine on nende paremaid filtratsioonitingimusi arvestades täiesti ootuspärane. Et götiidikuhjed moodustavad valdavalt kihilisust markeerivaid plaate (need ühinevad mõnikord mitmekorruselisteks karkassideks) ja tunduvalt vähemal hulgal kerajaid isomeetrilisi või mitmetsentrilisi vorme, siis võib arvata, et nende kujunemine leidis aset katageneetilisel teel, liivakivilasundis liikuva põhjavee toimel või koguni lasundi väljumisel maapinnale (Девон и карбон Прибалтики, 1981, 1k. 137). Pole võimatu, et kuhjed on tekkinud üsnagi hiljuti, võib-olla isegi alles Ahja jõe orundi eksisteerimise ajal, markeerides rauarikaste vete kunagisi allikaid orunõlvadel. Sel puhul pole ka välistatưd orgu täitvate kvaternaarisetete mõningane mõju konkretsiooniprotsessile, kas või näiteks eri vanusega setendite kontaktivööndis omapärase geokeemilise barjääri moodustamise teel. Mingeid kindlamaid tõendeid selle kohta pole.

Pealegi näitab röntgenanalüüs, et götiit on neis mōodustistes küll peitkristalliline, kuid selge kristallstruktuuriga, mis eristab teda kvaternaariajastu märksa amorfsema struktuuriga samalaadsetest ühenditest, näiteks tüüpilisest soorauast (Лаурингсон, Пиррус, 1985). Spektraalanalüüsi andmetel on götiit siin ka mangaanivaene $(0,06-0,25 \%)$, see viitab samuti konkretsioonide kujunemisele just põhjavete toimel. 
Konkretsioonide tühimikes esineva pudeda liiva lõimis ja mineraalne koostis Granulometric and mineral compositions of sand filling the cavities of concretions

A. Granulomeetriline koostis, \%

\begin{tabular}{|c|c|c|c|c|c|c|}
\hline \multirow[b]{2}{*}{ Nr. } & \multirow[b]{2}{*}{ Leiukoht } & \multirow[b]{2}{*}{ Iseloomustus } & \multicolumn{4}{|c|}{ Tera suurus, mm } \\
\hline & & & $>0,25$ & $0,25-0,1$ & $0,1-0,05$ & $<0,05$ \\
\hline 1. & $\begin{array}{l}\text { Karjäär Põlvast } \\
\text { pōhja pool }\end{array}$ & $\begin{array}{l}\text { Koorikulistele vormi- } \\
\text { dele kleepunud liiv }\end{array}$ & 9,0 & 18,0 & 72,0 & 1,0 \\
\hline 2. & Lutsu karjäär & $\begin{array}{l}\text { Liiv mitmekihilise koo- } \\
\text { rikulise konkretsiooni- } \\
\text { karkassi tühikutest }\end{array}$ & 85,9 & 7,6 & 5,4 & 1,1 \\
\hline 3. & 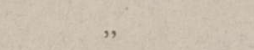 & 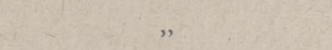 & 74,9 & 20,0 & 4,4 & 0,7 \\
\hline 4. & Marimäe karjäär & $\begin{array}{l}\text { Liiv ümara konkret- } \\
\text { siooni tuuma- } \\
\text { tühimikust }\end{array}$ & 71,4 & 17,1 & 8,6 & 2,9 \\
\hline
\end{tabular}

B. Kergefraktsiooni koostis, \%

\begin{tabular}{c|c|c|c|c|c}
\hline Nr. & Kvarts & Ortoklass & Mikrokliin & Plagioklass & Kaltsedon \\
\hline 1. & 89,3 & 9,6 & 0,4 & 0,7 & - \\
2. & 94,6 & 5,4 & - & - & - \\
3. & 91,0 & 7,1 & 0,5 & 1,4 & 0,4 \\
4. & 90,9 & 8,3 & - & 0,4 &
\end{tabular}

C. Raskefraktsiooni üldkoostis, \%

\begin{tabular}{|c|c|c|c|c|c|c|c|c|}
\hline $\mathrm{Nr}$. & $\begin{array}{l}\text { Raudhüd- } \\
\text { roksiid }\end{array}$ & $\begin{array}{l}\text { Leuko- } \\
\text { kseen }\end{array}$ & $\begin{array}{l}\text { Ilme- } \\
\text { niit }\end{array}$ & $\begin{array}{l}\text { Vilgud, } \\
\text { kloriit }\end{array}$ & $\begin{array}{c}\text { Glauko- } \\
\text { niit }\end{array}$ & $\begin{array}{l}\text { Dolo- } \\
\text { miit }\end{array}$ & Püriit & $\begin{array}{l}\text { Läbipaist- } \\
\text { vad alloti- } \\
\text { geensed } \\
\text { mineraalid }\end{array}$ \\
\hline 1. & 71,6 & 1,2 & 11,1 & 2,4 & - & 6,1 & - & 7,6 \\
\hline 2. & 75,4 & - & 6,8 & - & - & - & - & 17,8 \\
\hline 3. & 73,0 & 0,2 & 17,0 & - & - & - & - & 9,8 \\
\hline 4. & 20,4 & 3,9 & 49,4 & 1,5 & 0,4 & - & 0,7 & 23,7 \\
\hline
\end{tabular}

D. Läbipaistvate allotigeensete mineraalide koostis, \%

\begin{tabular}{|c|c|c|c|c|c|c|c|c|}
\hline Nr. & Tsirkoon & $\begin{array}{c}\text { Turma- } \\
\text { liin }\end{array}$ & Granaat & $\begin{array}{c}\text { Stauro- } \\
\text { liit }\end{array}$ & Disteen & Rutiil & Amfibool & Varia \\
\hline 1. & - & $(33,3)$ & $(66,7)$ & - & - & - & - & - \\
\hline 2. & 7,3 & 2,9 & 73,7 & 6,6 & 5,8 & 2,2 & 1,5 & - \\
\hline 3. & - & 0,8 & 69,5 & 20,3 & 8,5 & - & 0,8 & - \\
\hline 4.' & 20,6 & 5,9 & 36,7 & 20,6 & 8,8 & 2,9 & 1,5 & 3,0 \\
\hline
\end{tabular}


Ohikute uurimine näitas, et konkretsioonide raudoksiididega tsementeerumine toimus eelkõige terade ümber krustifikatsiooniliste götiidikilede (0,015-0,050 mm) moodustumise teel. Algselt olid need ilmselt kolloidsed, erinevate pinnalaengute toimel liibunud ümbrised, mis hiljem radiaalseteks kristallagregaatideks formeerusid ja kristalliseerumisjōuga purdterasid üksteisest kahe optimaalse kilepaksuse võrra eemale nihutasid. Tulemuseks kujunes tüüpiline põhitsement (teradel ei ole kokkupuutepunkte!) ja. selle optimaalne, kivimi algpooride mahtu pisut ületav hulk $(30-40 \%)$. Et protsess toimus nimelt nõnda, sellele viitavad selgesti õhikus nähtavad tumedad liitumisjooned krustifikatsioonikilede vahel, samuti kolme või enama tera vahele jäänud tühikud ning nende edasine täitumine paremini kristallunud hilisema götiidiga.

Kristalliseerumisjõud lōhkus tsemendi tungimisel lōhedesse märgatavalt ka paljusid purdteri, seda võib õhikutes näha. Tsement on kontaktidel purdteradega olnud sööbiva toimega, teravdanud nurki ja sopistanud terade pinda, kuid ei ole sügavamaid uuristustaskuid tekitanud. Enamsöövitunud pinnaga on konkretsioonides esinevad kvartsiitidest pärinevad polükristallilised terad, mida jämedamate kvartsiterade hulgas kohtab üsna sageli (kuni 18\%). Peale kvartsi ja kvartsiidi on konkretsioonide materjalis veel kaootiliselt paiknevaid muskoviidilehekesi (kuni 15\%) ja päevakive (plagioklassi, ortoklassi, mikrokliini - keskmiselt 5\%).

Konkretsioonide või koorikuliste karkasside õõnsustesse suletud liivast tehti proovid immersioonianalüüsiks. Tulemused on esitatud tabelis.

Liiva granulomeetriline koostis on muutlik, kuid devoni ümbriskivimi fooniga vỗreldes tunduvalt jämedateralisem: konkretsioonimoodustus on ilmselt eelistanud jämepurrurikkaid vahekihte.

Kerge fraktsiooni koostis ühtib õhikutes täheldatuga, analüüsiks ettevalmistamisel on välja uhutud vaid muskoviit.

Raskete mineraalide üldkoostis on väheinformatiivne ja varjutatud rohke raudhüdroksiidihulga poolt. Viimane aga näitab veenvalt, et konkretsioonidega vahetult põimuv liivmaterjal on samuti läbi teinud ilmse oksüdatsioonitsükli ja nähtavasti olnud ka pisikeste konkretsioonialgmete kujunemise tandriks.

Allotigeensete läbipaistvate mineraalide kooslus on aga kõige teaberikkam ja kinnitab veenvalt, et konkretsioonide-koorikute emakivimiks on olnud Burtnieki liivakivid. Sellest räägib suur granaadi hulk, eelkõige aga metamorfsetest lähtekivimitest pärinevate stauroliidi ja disteeni kōrge sisaldus, mis on vaadeldavale tasandile väga iseloomulik, seda eriti KaguEestis (Девон и карбон Прибалтики, 1981). Just see tunnus, aga ka ebapüsivate amfiboolide tühine sisaldus ei luba liivas oletada mingit kvaternaariliivade lisandit, isegi ebapuhtalt tehtud proovivötmise vöimalust silmas pidades.

Eeltoodu näitab, et mitme soodustava teguri kaasmõjul võis devoni kivimites asetleidnud teisejärguline konkretsiooniprotsess jätta kvaternaariajastu jäätumissetetesse märgatavaid jälgi ja anda neis lokaalseid kuhjeidki. Kui see protsess on seotud üksnes Burtnieki liivakividega Taevaskoja ümbruses, on materjali koondumine Põlva-Võru vahemikku päris mõistetav. Et samavanused kihid paljanduvad aga ka Võhandu alamjooksul (joon.), on võimalik neid kive leida ehk sellestki orust lõuna pool. Usaldusväärsem andmestik siit veel puudub ja üksikleiud Värska või Petseri piirkonnast võivad olla seletatavad mitmeti - ka loomuliku hajuvusega ülalkirjeldatud piirkonnast. Probleemi tuleb selgitada edaspidi. Seni ei ole niisuguseid konkretsioone liustikujõgede materjalis märgitud (Калм, 1986). 
Pirrus, E., Puustusmaa, R. 1991. Marimäe kõverad kivid. - Eesti Loodus, 6, 360-363. Девон и карбон Прибалтики. 1981. Зинатне, Рига.

Калм В. Э. 1986. Петрографический состав флювиогляциальных отложений Эстонской ССР. - Уч. зап. Тартуск. ун-та, 759. Литология платформенных пород Эстонии. Труды по геологии, Х. Тарту, 79-94.

Лауринасон А., Пиррус Э. 1985. К характеристике болотных руд железа, применяемых в первобытной металлургии Северной Эстонии. - Изв. АН ЭССР. Геол., $\mathbf{3 4}$, $2,68-72$.

Esitanud A. Raukas

Toimetusse saabunud

1. VII 1992

Anne-Liis KLEESMENT, Enn PIRRUS, and Rudolf PUUSTUSMAA

\section{OCCURRENCE OF DEVONIAN CONCRETIONS AS PEBBLES IN QUATERNARY SEDIMENTS}

In recent years glaciofluvial gravel deposits situated between Põlva and Võru, South Estonia (Fig.), have yielded abundantly platy, kidney-shaped, more rarely ballshaped nodules of dark brown colouring. Their composition shows iron hydroxide firmly cementing relatively coarse (up to $5 \mathrm{~mm}$ ) grains of quartz, feldspar, and micas. Roundness of these nodules with the average size of $5-10 \mathrm{~cm}$ increases regularly from north to south, but it can be observed distinctly already at the range of $20 \mathrm{~km}$. In the north, near Põlva, they are often represented by coarse angular clasts with a many-storeyed frame texture. The pattern of this frame, but also cores of some more southern rounded nodules contain soft sand. Its analysis (Table) has revealed the mineralogical composition identical with that of the sediments of the Burtnieki Stage exposed abundantly in the Ahja River Valley. Cementing iron oxide iś represented by recrystallized goethite, which forms fine $(0.015-0.050 \mathrm{~mm})$ rimmed overgrowths around mineral grains. Merging of such films, however, causes the development of matrix-rich cement with floating grains, commonly making up $25-40 \%$ of the nodule.

The nodules observed are fragments of big concretions, occurring very rarely in sandstones of the Burtnieki Stage. The abundance of these concretions in the Quaternary cover of this region can obviously be explained by the zigzag outline of the Ahja River Valley north of Põlva. The contact of the moving glacier with the exposed bedrock was extensive here, exaration of local Devonian sandstones was maximal. Weakly cemented sandstones broke and crumbled rapidly, particularly during the glaciofluvial process; hard concretions, however, preserved and enriched the pebble fraction of gravel.

\section{Анне-Лийс КЛЕЕСМЕНТ, Энн ПИРРУС, Рудольф ПУУСТУСМАА}

\section{ГАЛЬКООБРАЗНЫЕ ДЕВОНСКИЕ КОНКРЕЦИИ В ЧЕТВЕРТИЧНЫХ ОТЛОЖЕНияХ}

При разработке месторождений флювиогляциального гравия между Пылва и-Выру в Южной Эстонии (рисунок) часто встречаются плитчатые, причудливо-почковидные, реже шарообразные желваки темно-коричневого цвета. Составляющие их относительно грубые (до 5 мм) зерна кварца, полевых шпатов и слюды крепко сцементированы гидроокисью железа. Округленность желваков, размером в среднем 5-10 см, закономерно возрастает с севера на юг, что четко наблюдается уже в пределах 20 км. На 
севере - около Пылва - они нередко представлены крупными остроугольными обломками многоэтажно-каркасового строения. В текстуре этого каркаса, а также в ядрах некоторых округленных желваков с более южных участков присутствует сыпучий песок, который, судя по минеральному составу (таблица), идентичен отложениям буртниекского горизонта, обильно обнажающимся в долине р. Ахья. Цементирующая окись железа представлена раскристаллизованным гетитом, который образует тонкие $(0,015-$ 0,050 мм) крустификационные каемки вокруг минеральных зерен, а при сливании таких пленок между собой - базальный цемент, составляющий до 25-40\% объема желвака.

Рассматриваемые желваки являются фрагментами крупных катагенетических конкреций в песчаниках буртниекского горизонта, где они, хотя и редко, встречаются. Обогащенность этими конкрециями четвертичного покрова данного региона можно объяснить зигзагообразным очертанием участка древней долины р. Ахья севернее Пылва. Контакт двигавшегося ледника с обнажениями коренных пород был здесь протяженнее и, соответственно, экзарация местных песчаников девона - максимальной. Слабосцементированные песчаники быстро разрушились и рассыпались, особенно в цикле водноледниковой обработки, а крепкие конкреции сохранились и обогатили галечную фракцию гравия. Каких-либо достоверных данных о повышенной конкрециеносности материнских девонских песчаников в данном районе в настоящее время не имеется. 